\title{
Efficacy and Safety of Anterior Cervical Discectomy and Fusion (ACDF) Through Mini-Incision and Posterior Laminoplasty (LAMP) For Treatment of Long-Level Cervical Spondylosis
}

\author{
Yingkai Zhang \\ Jinshan Hospital of Fudan University \\ Guangling Yang \\ Shanghai Public Health Clinical Center \\ Tianyao Zhou \\ Zhongshan Hospital Fudan University \\ Yanchao Chen \\ Shanghai Public Health Clinical Center \\ Zhenchao Gao \\ Shanghai Public Health Clinical Center \\ Weili Zhou \\ Shanghai Public Health Clinical Center \\ Yutong Gu ( $\nabla 47574313 @ q q . c o m$ ) \\ Zhongshan Hospital Fudan University
}

\section{Research Article}

Keywords: ACDF, LAMP, long-level cervical spondylosis, mini-incision

Posted Date: December 30th, 2021

DOI: https://doi.org/10.21203/rs.3.rs-1199853/v1

License: (c) (i) This work is licensed under a Creative Commons Attribution 4.0 International License. Read Full License 


\section{Abstract}

Background: The efficacy and safety of anterior cervical discectomy and fusion (ACDF) through miniincision and posterior laminoplasty for long-level cervical spondylosis were investigated.

Method: From January 2018 to September 2019, clinical patients data with 3-4 segments (C3-7) cervical spondylotic radiculopathy, cervical spondylotic myelopathy, or mixed cervical spondylosis who received ACDF (42 cases) throughwith mini-incision or LAMP (36 cases) treatment were retrospectively collected and analyzed. The operative time, bleeding volume, incisive length, and hospital stay were recorded. Moreover, the intervertebral height, functional segment height, cervical lordosis, cervical hyperextension and hyperflexion range-of-motion (ROM) and ROM in all directions of the cervical spine before and after the operation were measured. Additionally, all relevant postoperative complications were also recorded. Then, the therapeutic effects of both surgical methods were investigated.

Results: Patients in the ACDF group had less bleeding, shorter incision, and fewer hospitalization days than the LAMP group. Postoperative intervertebral height and functional segment height in the ACDF group were significantly higher than those before the operation, and postoperative functional segment height of the ACDF group was significantly higher than that of the LAMP group. Moreover, the postoperative cervical lordosis angle in the ACDF group was significantly larger than the LAMP group. There was no significant difference between preoperative and postoperative ROM in all directions of the cervical spine for the two groups.

Conclusions: Both ACDF through mini-incision and LAMP are effective treatments for long-level cervical spondylosis. However, ACDF through mini-incision shows minor trauma, less bleeding, fast recovery, and it is beneficial for cervical lordosis reconstruction.

\section{Introduction}

Cervical spondylosis (CS) is the most common nerve root and spinal cord degenerative disorder in adults whose diagnosis includes symptoms, signs, and various imaging examinations [1]. The treatment for CS includes anterior and posterior surgery [2]. In 1958, anterior cervical discectomy and fusion (ACDF) were first proposed to treat CS [3]. Since then, the safety and effectiveness of short-segment ACDF to alleviate cervical nerve symptoms have been verified by many studies; however, long-stage ( $>3$ segments) ACDF was seldomly reported $[4,5]$. Additionally, it has been reported that long-segment surgery might induce several complications such as dysphagia [6, 7]. In 1981, Hirabayashi et al. [8] first performed posterior laminoplasty (LAMP) to treat the ossification of the posterior longitudinal ligament (OPLL). Although the pathological factors leading to compression had not been treated, the pressure on the nerve could be indirectly alleviated as the nerve drifted backward like a bowstring following decompression. Nevertheless, several patients who received long-segment LAMP showed C5 paralysis, reduction of cervical range-of-motion (ROM), axial cervical pain, and other complications [9]. Due to poor daily habits combined with the aging of the general population, the incidence of long-level CS has increased. However, 
there remains controversy regarding the surgical treatment of long-level CS in the absence of severe OPLL [10-12]. This study aims to investigate the clinical efficacy of ACDF through mini-incision and LAMP in long-level CS treatment. These findings will provide greater insight to clinicians and can be used to improve patient outcomes.

\section{Materials And Methods}

This study was approved by the ethics committee of Zhongshan Hospital Fudan University and informed consent was obtained from all patients.

From January 2018 to September 2019, clinical data were retrospectively collected from patients with long-level (3-4 segments) CS who received ACDF (42 cases) or LAMP (36 cases) treatment. All patients had symptoms and signs of a nerve root or spinal cord compression, and where conservative treatment was found to be ineffective. To avoid bias, only cases with long-level cervical disc herniation (cases without severe OPLL) that could be treated by ACDF or LAMP were included.

Inclusive criteria: (1) degenerative cervical spondylosis; (2) complete image data; (3) the follow-up time > 24 months; (4) cervical kyphosis $<10^{\circ}$.

Exclusive criteria: 1) developmental cervical stenosis; 2) OPLL; 3) severe cervical spondylolisthesis; 4) cervical kyphosis of $>10^{\circ}$ or cases with negative modified K-line on magnetic resonance imaging; 5) space-occupying lesions of the cervical spine; 6 ) cervical trauma; 7) cervical revision surgery; 8 ) incomplete imaging data or the follow-up time $<24$ months.

\section{Surgical procedures}

Before ACDF, patients underwent general anesthesia and were placed in the neck hyperextension supine position. A 2 3 cm right anterior transverse incision was made approximately parallel to the lower edge of the thyroid cartilage. The skin, subcutaneous superficial fascia, platysma, and deep fascia were then cut in turn. The approach extended between the cervical visceral and vascular sheath to expose the diseased intervertebral space located at the most cephalic location from C3-7. Vertebral nails were then drilled into the head and tail vertebral bodies, respectively. The tail vertebral body nail deviated to the lower endplate. After partial discectomy, a Caspar distractor was used to open the diseased intervertebral space. The nucleus pulposus was removed, the cartilage of the endplate was scraped, and the osteophyte at the posterior edge of the vertebral body was removed. The posterior longitudinal ligament was then opened to expose the dual sac. The bilateral intervertebral foramen was then enlarged to complete the neurologic decompression. After the model test, a suitable ROI-C plug-in interbody fusion cage (Zimmer Holdings, Inc. America) filled with allograft bone was inserted into the intervertebral space. Once the position of the cage was satisfactory, as assessed by fluoroscopy, the self-locking plug-in was inserted. The intervertebral space of other lesions was treated using the same method. Once completed, each layer was closed with a suture and a negative pressure drainage tube was placed (Figure 1). After the operation, neck immobilization was maintained for 4 weeks. (Figure 1). 
LAMP was performed as previously described [13]. Briefly, the paravertebral muscles were detached from both the right and left sides of the spinous processes. The laminae were split between the laminae and facets at the unilateral side with severe neurologic compression and, using a high-speed air-burr drill, gutters were made between the laminae and facets at the contralateral side which acts as hinges. The laminae and spinous processes were turned over and small plates (Weigao Holdings, Inc. China) were fixed between the laminae and facets at the open side. Neurologic decompression was performed for 3 or 4 levels from C3-7. Each layer was closed with a suture and a negative pressure drainage tube was placed. Patients were instructed to wear a neck collar for 3-4 weeks (Figure 2).

When the drainage volume $<20 \mathrm{ml} / 24 \mathrm{~h}$ remove the drainage tube and Patients can begin to walk. A single, experienced spine surgeon performed the operations mentioned above.

\section{Data recording}

\section{The operation-related data:}

Operation time, operation bleeding, incision length, and average hospital stay were collected for subsequent analysis.

\section{Clinical follow-up data:}

The JOA score, JOA score improvement rate, and NDI score, VAS of the upper limb before the operation and 24 months after the operation were recorded. Neurologic function and cervical spine function before and after the operation were evaluated. ROM in all directions of the cervical spine before and 24 months after the operation was measured, including flexion, extension, lateral flexion, and rotation, and the loss rate of ROM was calculated (Figure 3)[14]. The subjective satisfaction of the patients regarding clinical efficacy at 2-year follow-up was evaluated based on Odom criteria.[15]

\section{Imaging data}

The anterioposterior and lateral $\mathrm{x}$-ray, as well as hyperextension and hyperflexion lateral $\mathrm{x}$-ray of the cervical spine, 3-D CT were taken before, immediately after the operation, as well as at 3, 6, 12, and 24 months after the operation. The preoperative and postoperative intervertebral height, functional (surgical) segment height, cervical lordosis angle (C2-7 Cobb angle), cervical hyperextension and hyperflexion ROM (cervical lordosis angle difference was based on hyperextension and hyperflexion lateral film) were measured and whether there was subsidence of the fusion cage after the operation (loss of intervertebral height greater than $2 \mathrm{~mm}$ was defined as subsidence) was identified. The classification standard of anterior bone graft fusion was used for the fusion evaluation on CT. [16] For instance, Grade I (apparent fusion) is defined as visible bone trabeculae formation and penetration of the endplates of the upper and lower vertebral bodies; Grade II, (possible fusion) as defined by an intact bone graft and no transparent band around the head or tail, however, it was not completely remolded and integrated into the upper and lower vertebral bodies; Grade III (possibly failed fusion) as defined as an intact bone graft and the presence of a transparent band at the head or tail; Grade IV (failed fusion) defined as the bone graft being 
absorbed or the subsidence of the fusion cage; Grade V (unable evaluation) characteristic of cases where bone graft displacement was apparent.

Postoperative complications included C5 nerve root paralysis, cerebrospinal fluid leakage, axial pain, dysphagia, and other complications. The postoperative dysphagia was evaluated according to Bazaz criteria i.e., 0 : no dysphagia, 1: mild or rare dysphagia, 2: moderate or occasional dysphagia, and 3: severe or frequent dysphagia. [17]

\section{Statistical analysis}

Data analysis was performed using the SPSS 20.0 statistical software. The Kolmogorov-Smirnov test was used to identify the normality, and all data conformed to the normal distribution. Measured data were expressed as $x \pm s$ and the independent sample t-test was used to compare two groups and in groups. The count data were compared by $\mathrm{x} 2$ test between groups. $\mathrm{P}$ values $<0.05$ were considered statistically significant.

\section{Results}

Using the inclusion/exclusion criteria detailed above, 78 patients were retrospectively selected for this study. Based on the surgical method used, the patients were divided into 42 cases in the ACDF group (25 cases with 3 segments and 17 cases with 4 segments, a total of 143 segments) and 36 cases in the LAMP group ( 20 cases with 3 segments and 16 cases with 4 segments, a total of 124 segments) (Table 1). 
Table 1

Sample characteristics of Groups A and B

\begin{tabular}{|llll|}
\hline Item & Group A & Group B & P-value \\
\hline Age (year) & $57.9 \pm 8.9$ & $62.1 \pm 9.2$ & 0.215 \\
\hline Gender (n) & & & \\
\hline Male & 29 & 25 & \\
\hline Female & 13 & 11 & \\
\hline Follow-up time (months) & $41.2 \pm 3.2$ & $40.9 \pm 2.8$ & 0.767 \\
\hline Operation time (minutes) & $127.5 \pm 30.0$ & $131.2 \pm 29.4$ & 0.534 \\
\hline Blood loss (mL) & $50.5 \pm 23.8$ & $326.4 \pm 60.4$ & $0.015^{\star}$ \\
\hline Remove the drainage tube(days) & $2(1-2)$ & $5(3-7)$ & $0.026^{\star}$ \\
\hline hospital stay(days) & $4(3-7)$ & $7(5-14)$ & $0.031^{*}$ \\
\hline Surgical incision(cm) & & & \\
\hline Three-level operation & $2.5 \pm 0.4$ & $10 \pm 2.6$ & $<0.01^{*}$ \\
\hline Four-level operation & $3.4 \pm 0.5$ & $13 \pm 2.2$ & $<0.01^{*}$ \\
\hline Complications & & & \\
\hline Axial pain & $0(0 \%)$ & $3(8.33 \%)$ & \\
\hline C5 palsy & $0(0 \%)$ & $2(5.56 \%)$ & \\
\hline Transient dysphagia & $0(0 \%)$ & $0(0 \%)$ & \\
\hline CSF leakage & $0(0 \%)$ & $1(2.78 \%)$ & \\
\hline Abbreviations, CSF: cerebrospinal fluid. *p $<0.05$ versus Group B using t-test. \\
\hline
\end{tabular}

No significant difference in gender, age, JOA, VAS score of the upper limb, NDI score, cervical intervertebral height, functional segment height, lordosis angle, hyperextension and hyperflexion ROM, cervical ROM, and the surgical segments was observed between the two groups. The blood loss of the LAMP group was significantly higher than that of the ACDF group $(P<0.05)($ Table 1$)$. The surgical incision and hospital stay of the ACDF group were significantly shorter than that of the LAMP group $(\mathrm{P}<$ 0.05). There was no significant difference in the operative time between the two groups. The drainage tube removal time (median) was 2 (range 1-2) days after operation in the ACDF group and 5 (range 3-7) days after operation in the LAMP group. (Table 1 )

\section{Clinical efficacy evaluation}


The postoperative JOA score was significantly improved in both groups $(P<0.05)$. Additionally, there was no significant difference in the improvement rate of the JOA score between the two groups. The postoperative VAS scores of the upper limb in the two groups were significantly dropped $(P<0.05)$. There was no significant difference in the improvement rate as measured by the NDI score between the two groups (Table 2).

Table 2

NDI, JOA Scores and VAS of the upper limb of Groups A and B

\begin{tabular}{|c|c|c|c|c|}
\hline & Group & Preoperation & 2 years after operation & P-value \\
\hline \multirow[t]{3}{*}{ NDI score } & Group A & $59.3 \pm 5.7$ & $59.3 \pm 5.7$ & 0.784 \\
\hline & Group B & $59.3 \pm 5.7$ & $29.8 \pm 10.1$ & 0.854 \\
\hline & $P$ value & 0.814 & 0.758 & \\
\hline \multirow[t]{3}{*}{ JOA score } & Group A & $10.2 \pm 3.6$ & $14.6 \pm 1.2$ & $0.048^{*}$ \\
\hline & Group B & $9.7 \pm 4.2$ & $14.2 \pm 1.7$ & $0.035^{\star}$ \\
\hline & $P$ value & 0.757 & 0.325 & \\
\hline \multirow[t]{3}{*}{ VAS of the upper limb } & Group A & $5(3-8)$ & $2(2-3)$ & $0.026^{*}$ \\
\hline & Group B & $5(3-7)$ & $2(2-3)$ & $0.037^{*}$ \\
\hline & $P$ value & 0.685 & 0.568 & \\
\hline
\end{tabular}

All patients were evaluated according to the clinical efficacy of Odom 2 years following surgery. In the ACDF group, 32 cases were excellent, and 10 cases were good, with an excellent rate of $100 \%$. In the LAMP group, 28 cases were excellent, and 8 cases were good, with an excellent rate of $100 \%$. There were no significant differences in ROM in all directions and ROM loss rate between the two groups (Table 6). 
Table 6

Cervical range-of-motion of Groups A and B

\begin{tabular}{|c|c|c|c|c|c|}
\hline & Group & Preoperative & Postoperative & $\begin{array}{l}P \\
\text { value }\end{array}$ & $\begin{array}{l}\text { loss } \\
\text { ratio }\end{array}$ \\
\hline \multirow[t]{3}{*}{ Flexion } & $\begin{array}{l}\text { Group } \\
\text { A }\end{array}$ & $40.63 \pm 4.79$ & $31.25 \pm 4.28$ & 0.134 & $\begin{array}{l}19.65 \\
\pm 6.67\end{array}$ \\
\hline & $\begin{array}{l}\text { Group } \\
\text { B }\end{array}$ & $42.78 \pm 5.58$ & $36.85 \pm 6.64$ & 0.239 & $\begin{array}{l}14.62 \\
\pm 7.95\end{array}$ \\
\hline & $\begin{array}{l}\mathrm{P} \\
\text { value }\end{array}$ & 0.862 & 0.357 & & 0.246 \\
\hline \multirow[t]{3}{*}{ Extension } & $\begin{array}{l}\text { Group } \\
\text { A }\end{array}$ & $38.75 \pm 4.65$ & $32.54 \pm 7.38$ & 0.147 & $\begin{array}{l}15.85 \\
\pm 8.69\end{array}$ \\
\hline & $\begin{array}{l}\text { Group } \\
\text { B }\end{array}$ & $39.82 \pm 5.85$ & $34.38 \pm 6.25$ & 0.132 & $\begin{array}{l}12.89 \\
\pm 4.65\end{array}$ \\
\hline & $\begin{array}{l}\mathrm{P} \\
\text { value }\end{array}$ & 0.785 & 0.845 & & 0.345 \\
\hline \multirow[t]{3}{*}{ Lateral bending (L) } & $\begin{array}{l}\text { Group } \\
A\end{array}$ & $39.69 \pm 4.27$ & $31.85 \pm 4.41$ & 0.067 & $\begin{array}{l}17.59 \\
\pm 6.54\end{array}$ \\
\hline & $\begin{array}{l}\text { Group } \\
\text { B }\end{array}$ & $45.65 \pm 6.45$ & $37.45 \pm 6.68$ & 0.075 & $\begin{array}{l}17.78 \\
\pm 5.36\end{array}$ \\
\hline & $\begin{array}{l}\mathrm{P} \\
\text { value }\end{array}$ & 0.357 & 0.247 & & 0.825 \\
\hline \multirow[t]{3}{*}{ Lateral bending $(\mathrm{R})$} & $\begin{array}{l}\text { Group } \\
\text { A }\end{array}$ & $41.37 \pm 7.85$ & $37.85 \pm 5.56$ & 0.127 & $\begin{array}{l}9.75 \pm \\
3.56\end{array}$ \\
\hline & $\begin{array}{l}\text { Group } \\
\text { B }\end{array}$ & $43.82 \pm 6.35$ & $38.15 \pm 6.15$ & 0.097 & $\begin{array}{l}11.54 \\
\pm 4.52\end{array}$ \\
\hline & $\begin{array}{l}P \\
\text { value }\end{array}$ & 0.687 & 0.728 & & 0.358 \\
\hline \multirow{3}{*}{$\begin{array}{l}\text { Axial rotation } \\
\text { (L) }\end{array}$} & $\begin{array}{l}\text { Group } \\
\text { A }\end{array}$ & $72.50 \pm 6.58$ & $55.31 \pm 8.65$ & 0.125 & $\begin{array}{l}24.58 \\
\pm 6.74\end{array}$ \\
\hline & $\begin{array}{l}\text { Group } \\
\text { B }\end{array}$ & $77.24 \pm 8.41$ & $60.96 \pm 9.82$ & 0.238 & $\begin{array}{l}22.68 \\
\pm 7.54\end{array}$ \\
\hline & $\begin{array}{l}\mathrm{P} \\
\text { value }\end{array}$ & 0.278 & 0.375 & & 0.534 \\
\hline \multirow{2}{*}{$\begin{array}{l}\text { Axial rotation } \\
\text { (R) }\end{array}$} & $\begin{array}{l}\text { Group } \\
\text { A }\end{array}$ & $70.59 \pm 7.52$ & $53.95 \pm 9.54$ & 0.234 & $\begin{array}{l}24.28 \\
\pm 6.15\end{array}$ \\
\hline & $\begin{array}{l}\text { Group } \\
\text { B }\end{array}$ & $75.65 \pm 8.40$ & $61.25 \pm 6.96$ & 0.127 & $\begin{array}{l}18.36 \\
\pm 7.96\end{array}$ \\
\hline
\end{tabular}

ROM: range of motion* $\mathrm{p}<0.05$ versus Group B using t-test. 


\begin{tabular}{|c|c|c|c|c|c|}
\hline & Group & Preoperative & Postoperative & $\begin{array}{l}P \\
\text { value }\end{array}$ & $\begin{array}{l}\text { loss } \\
\text { ratio }\end{array}$ \\
\hline & $\begin{array}{l}\mathrm{P} \\
\text { value }\end{array}$ & 0.251 & 0.287 & & 0.081 \\
\hline \multirow[t]{3}{*}{$\begin{array}{l}\text { hyperextension and hyperflexion } \\
\text { Cervical ROM }\end{array}$} & $\begin{array}{l}\text { Group } \\
\text { A }\end{array}$ & $41.5 \pm 11.6$ & $26.3 \pm 7.6$ & $0.015^{\star}$ & $\begin{array}{l}36.58 \\
\pm 5.34\end{array}$ \\
\hline & $\begin{array}{l}\text { Group } \\
\text { B }\end{array}$ & $43.6 \pm 12.4$ & $36.2 \pm 8.5$ & $0.037^{*}$ & $\begin{array}{l}16.27 \\
\pm 4.78\end{array}$ \\
\hline & $\begin{array}{l}\mathrm{P} \\
\text { value }\end{array}$ & 0.571 & 0.125 & & $0.021^{\star}$ \\
\hline
\end{tabular}

\section{Imaging assessment}

The postoperative intervertebral height and functional segment height of the ACDF group were significantly higher than those before the operation $(P<0.05)($ Table 3$)$. Additionally, the postoperative functional segment height of the ACDF group was significantly higher than that of the LAMP group $(\mathrm{P}<$ $0.05)$ (Table 4). The cervical lordosis increased significantly in the ACDF group $(P<0.05)$ and decreased in the LAMP group following corrective surgery. The postoperative cervical lordosis of the ACDF group was significantly higher than that of the LAMP group $(P<0.05)$ (Table 5). The ROM of cervical hyperextension and hyperflexion decreased in both groups, but there was no statistical difference $(P>$ 0.05) (Table 6). At 6 months post-operation, 82 cases with Grade I fusion and 60 cases with Grade II fusion were observed in the ACDF group (Table 3). One case experienced Grade IV fusion cage sinking; the fusion rate was determined to be $99.3 \%$ (142/143).

Table 3

Average intervertebral height of patients with anterior cervical disorder

\begin{tabular}{|lclll|}
\hline & Preoperative & $\begin{array}{l}\text { Immediately after } \\
\text { operation }\end{array}$ & $\begin{array}{l}\text { 2 years after } \\
\text { operation }\end{array}$ & $\begin{array}{l}\text { P- } \\
\text { value }\end{array}$ \\
\hline $\begin{array}{l}\text { Average intervertebral height } \\
(\mathrm{mm})\end{array}$ & $3.91 \pm 0.52$ & $4.84 \pm 0.62$ & $4.75 \pm 0.65$ & 0.857 \\
\hline$* \mathrm{p}<0.05$ versus postoperative using t-test. & & & \\
\hline
\end{tabular}


Table 4

The total anterior length of fusion segments in Groups A and B

\begin{tabular}{|c|c|c|c|c|}
\hline & & Preoperative & Postoperative & $\begin{array}{l}\mathrm{P}- \\
\text { value }\end{array}$ \\
\hline \multirow[t]{3}{*}{$\begin{array}{l}\text { Total anterior length of } 3 \text { fusion segments } \\
(\mathrm{mm})\end{array}$} & $\begin{array}{l}\text { Group } \\
\text { A }\end{array}$ & $58.7 \pm 3.2$ & $62.3 \pm 2.9$ & $0.048 *$ \\
\hline & $\begin{array}{l}\text { Group } \\
\text { B }\end{array}$ & $57.4 \pm 3.1$ & $57.3 \pm 3.0$ & 0.957 \\
\hline & $P$ value & 0.752 & 0.035 & \\
\hline \multirow[t]{3}{*}{$\begin{array}{l}\text { Total anterior length of } 4 \text { fusion segments } \\
(\mathrm{mm})\end{array}$} & $\begin{array}{l}\text { Group } \\
\text { A }\end{array}$ & $74.6 \pm 4.1$ & $80.7 \pm 3.5$ & $0.037^{*}$ \\
\hline & $\begin{array}{l}\text { Group } \\
\text { B }\end{array}$ & $73.8 \pm 3.6$ & $73.6 \pm 3.2$ & 0.986 \\
\hline & $P$ value & 0.685 & 0.357 & \\
\hline
\end{tabular}

Table 5

C2-7 Cobb angle of Groups A and B

\begin{tabular}{|llllll|}
\hline & Group & Preoperative & Postoperative & $\begin{array}{l}\text { C2-7 Cobb } \\
\text { angle } \\
\text { improvement }\end{array}$ & $\begin{array}{l}\text { P- } \\
\text { value }\end{array}$ \\
\hline $\begin{array}{l}\text { C2-7 Cobb angle/ cervical } \\
\text { lordosis }\left(^{\circ}\right)\end{array}$ & $\begin{array}{llll}\text { Group } \\
\text { A }\end{array}$ & $8.7 \pm 4.2$ & $22.5 \pm 6.9$ & $13.8 \pm 3.6$ & $<.01^{*}$ \\
\hline & $\begin{array}{l}\text { Group } \\
\text { B }\end{array}$ & $11.4 \pm 5.4$ & $11.2 \pm 5.6$ & $-0.2 \pm 4.7$ & 0.958 \\
\hline & $\begin{array}{l}\text { P } \\
\text { value }\end{array}$ & 0.758 & 0.258 & 0.178 & \\
\hline${ }^{*} \mathrm{p}<0.05$ versus Group B using t-test. & & & & \\
\hline
\end{tabular}

In the group of LAMP, three patients with axial pain complained of pain from the neck to the periscapular or shoulder area; however, the symptoms were relieved with non-steroidal anti-inflammatory drugs. The primary manifestation of $\mathrm{C} 5$ paralysis was deltoid weakness. After conservative treatment, the muscle strength of 2 patients returned to normal within 3 months. One case with cerebrospinal fluid leakage healed following 2 weeks of bed rest. In ACDF group, there was no case of dysphagia following operation.

\section{Discussion}

Currently, long-level CS treatment is controversial.[18] Several studies have compared the efficacy of anterior decompression and posterior decompression for the treatment of long-level CS; however, no 
consensus as to the best treatment strategy has been reached. ACDF is the most common surgical intervention for CS, especially for treating single-segment CS.[19] ACDF can directly remove compression on the ventral side and open the intervertebral space, effectively restoring cervical lordosis, enlarging the intervertebral foramen, and reconstructing the stability of the degenerative segments. Treatment strategies such as the use of fusion cage and titanium plate fixation systems have been widely used in conventional ACDF[3]. Clinically, ACDF has been used to treat 1-2 segments of CS and is considered a safe and effective surgical method for cervical degenerative diseases. [20] However, the posterior opendoor can enlarge the practical volume of the spinal canal to decompress the spinal cord. Although the pathology due to compression is not eliminated, compression on the spinal cord can be indirectly reduced. This is because the spinal cord drifts backward like a bowstring after the decompression[8]. Improving patients' neurologic symptoms is the ultimate goal of the operation, regardless of the operation method utilized.[21] Previous clinical studies have shown that both surgical methods can effectively alleviate neurologic symptoms.[22] In agreement with these data, we observed no significant differences between the two surgical methods in regards to their ability of alleviating neurologic symptoms. However, ACDF could be performed level by level through mini-incision resulting from the elasticity of neck skin and enough space between visceral sheath and cervical spine, and nearly no damage to paravertebral muscle occurred. In the ACDF group, the incision length was about $3 \mathrm{~cm}$, the bleeding was about $50 \mathrm{ml}$, the drainage tube was removed 1-2 days after surgery, and the hospital stay was about 4 days, while the LAMP incision length was about $10 \mathrm{~cm}$, the average bleeding was over $300 \mathrm{ml}$, and the drainage tube was removed about 5 days after surgery, and the hospital stay was about 7 days. The damage in mini-incision ACDF group was significantly less than that in LAMP group, and the recovery after ACDF was faster.

Consistent with previous studies, we found that cervical lordosis (C2-7) in the ACDF group increased significantly after the operation. Furthermore, the cobb angle of C2-7 in the LAMP group did not change significantly after the operation.[23] ACDF has the advantage of reconstructing cervical lordosis. It can not only restore normal physiological curvature but also restore the height of fused segments. Although ACDF is superior to LAMP in reconstructing cervical lordosis, ACDF limits C2-7 movement to some extent. Wu et al. reported that the ROM of cervical flexion and extension decreased by $28.2 \%$ and that the range of cervical rotation decreased by $14.1 \%$ after 3-level or 4-level ACDF treatment. [24] In this study, the ROM of cervical lordosis hyperextension and hyperflexion was decreased by approximately $36 \%$ in the ACDF group. Theoretically, LAMP does not affect the movement of the cervical spine. However, lamina selffusion, muscle degeneration, and the facet joint may be essential factors contributing to reduced ROM of cervical lordosis hyperextension and hyperflexion after LAMP treatment. The ROM loss of cervical lordosis hyperextension and hyperflexion after LAMP is common in clinical studies $(47.3 \%)$. $[25,26]$ In this study, the ROM loss rate of cervical lordosis hyperextension and hyperflexion in the ACDF group was higher than that in the LAMP group. However, there was no significant difference in the ROM loss rate in all directions of the cervical spine after the operation between the ACDF and the LAMP groups. There was no significant difference in ROM in all directions of the cervical spine between before and after the operation in each group. This may be because the atlantooccipital and atlantoaxial joints play a 
significant role in flexion, extension, lateral flexion, and axial rotation.[14] Hence, it can be concluded that 3-4-level ACDF and LAMP have a negligible effect on the ROM of the cervical spine. Previous studies suggest that the increased decompression and fusion segments contribute to the increased probability of postoperative non-fusion and pseudo-joint.[27] In this study, the fusion rate was $99.3 \%$ (142/143) in ACDF group, indicating that the ROI-C plug-in self-locking fusion cage obtained robust and reliable fusion in the application of 3-4 segments. This observation may be associated with the unique anatomical design of the ROI-C plug-in interbody fusion system. Further, this design could provide ample bone graft space and make close bone contact with the endplate. Additionally, the titanium plug-in that is inserted into the vertebral body through the endplate may improve stability and facilitate early fusion. One case with the subsidence of the C6/7 segment fusion cage was defined as Grade IV fusion in 4-segment ACDF. The $\mathrm{C6} / 7$ was at the tail end and the tension generated by the mini-incision pushed the holder rod of the fusion cage to the head end. If the cage was inserted without following the direction of the intervertebral space, it was likely to enter the lower endplate of $\mathrm{C7}$ or even the vertebral body resulting in subsidence. So the cage should be inserted parallelly to the intervertebral space, and if necessary, fluoroscopy could be used to confirm the position of cage. Then, the self-locking plug-in was knocked in when the cage was holded at the best position, which could avoid the subsidence of the fusion cage.

Both ACDF and LAMP are associated with several possible complications. Of such complications, axial pain is typical, especially in LAMP. In the current study, 42 patients in the ACDF group did not experience axial pain and 3 patients in the LAMP group reported posterior axial pain. It is understood that ligament injury of the posterior cervical muscle caused by LAMP is the main cause of potentially chronic axial pain.[28-30] Chiba et al.[31] reported that up to $28 \%$ of patients treated with LAMP experienced axial pain 14 years after the operation. However, the anterior approach caused less muscle damage. Furthermore, these patients were less likely to develop axial pain and recovered faster after the operation.

Anterior cervical surgery usually causes dysphagia. Currently, it is considered that dysphagia may be related to increased esophageal pressure during plate implantation or postoperative soft-tissue edema, [32] esophageal injury, postoperative hematoma, and the formation of adhesion around the implanted cervical plate, $[17,33]$ Several experts also indicate that dysphagia is related to the thickness of the titanium plate at the fusion level.[34] In this study, no patients developed dysphagia following ACDF treatment. No profile higher than the surface of the vertebral body after the ROI-C plug-in fusion cage was completely inserted into the intervertebral space, could avoid contact between the implant and the esophagus or other soft tissues in front of the cervical spine. This separation could eliminate any mechanical stimulation of implantation against esophagus as well as potentially avoid dysphagia. From these observations, the ROI-C plug-in fusion cage is considered a safe and effective treatment for longlevel cervical disc herniation .

C5 paralysis is a common complication of cervical surgery. Shou et al. [35] conducted a meta-analysis of available clinical data and found that the incidence of C5 paralysis in the ACDF and LAMP groups was $3.3 \%$ and $5.1 \%$, respectively. In this study, the incidence of C5 paralysis in the LAMP group was $5.56 \%$. The increased incidence may be attributed to the amplification of the spinal canal which in turn 
facilitates the drifting of the spinal cord to the dorsal side; thus, involving the $\mathrm{C} 5$ nerve root after the cervical posterior open-door surgery. The ACDF patients did not develop C5 paralysis, which may be explained by the fact that neurologic decompression in ACDF was limited to the intervertebral space, conventional enlargement of the bilateral intervertebral foramen and no overdistraction of intervertebral space. To avoid C5 paralysis, Tsuji et al. [36] limited the lamina opening angle to $53.5^{\circ}$ to minimize spinal cord drift. Katsumi et al. [37] reduced the incidence of $\mathrm{C} 5$ paralysis by preventive decompression of the bilateral C4-5 intervertebral foramen. Large intervertebral height, over correction of cervical curvature, and a narrow $\mathrm{C} 4-5$ intervertebral foramen may be risk factors for $\mathrm{C} 5$ paralysis following ACDF treatment. Therefore, a reasonable plan of cervical sagittal reconstruction before the operation may reduce the incidence of C5 paralysis following ACDF treatment.

\section{Conclusions}

Both ACDF through mini-incision and LAMP are effective treatments of long-level CS. However, ACDF through mini-incision shows minor trauma, less bleeding, fast recovery and it is beneficial for cervical lordosis reconstruction.

\section{Declarations}

\section{Ethics approval and consent to participate}

Retrospective clinical study was approved by Jinshan Hospital of Fudan University's institutional review board (JIEC 2021-S21-01). This study was conducted in accordance with the Declaration of Helsinki. All the patients consented to participate in this study, and informed consents were signed by themselves in all instances.

\section{Consent for publication}

Written informed consent was obtained from the patients' guardians for publication of clinical data.

\section{Availability of data and materials}

The datasets of the current study are available from the corresponding author upon reasonable request.

\section{Competing interests}

The authors declare that they have no competing interests.

\section{Funding}

This study was funded by Jinshan Hospital of Fudan University (No.JYQN-LC-202107), The funding bodies played no role in the design of the study and collection, analysis, and interpretation of data and in writing the manuscript. 


\section{Authors' contributions}

ZYK and YGL involved in making the conception and design of research and carried out drafing of the article. GYT carried out the acquisition of data and made a final approval and guarantor of the manuscript. ZWL participated in making the conception and design of the study, carried out the acquisition of data and made a final approval and guarantor of the manuscript. ZTY contributed on collecting parents' information. CYC contributed on collecting parents' information. GZC contributed on collecting parents' information. All authors read and approved the final manuscript.

\section{Footnotes}

\section{Publisher's Note}

Springer Nature remains neutral with regard to jurisdictional claims in published maps and institutional affiliations.ZYK and YGL contributed equally to this work.

\section{References}

1. Nouri A, Tetreault L, Singh A, Karadimas SK, Fehlings MG. Degenerative Cervical Myelopathy: Epidemiology, Genetics, and Pathogenesis. Spine (Phila Pa 1976). 2015. 40(12): E675-93.

2. Fehlings MG, Wilson JR, Kopjar B, et al. Efficacy and safety of surgical decompression in patients with cervical spondylotic myelopathy: results of the AOSpine North America prospective multi-center study. J Bone Joint Surg Am. 2013. 95(18): 1651-8.

3. SMITH GW, ROBINSON RA. The treatment of certain cervical-spine disorders by anterior removal of the intervertebral disc and interbody fusion. J Bone Joint Surg Am. 1958. 40-A(3): 607-24.

4. Luo J, Cao K, Huang S, et al. Comparison of anterior approach versus posterior approach for the treatment of multilevel cervical spondylotic myelopathy. Eur Spine J. 2015. 24(8): 1621-30.

5. Liu X, Min S, Zhang H, Zhou Z, Wang H, Jin A. Anterior corpectomy versus posterior laminoplasty for multilevel cervical myelopathy: a systematic review and meta-analysis. Eur Spine J. 2014. 23(2): 362-72.

6. Fountas KN, Kapsalaki EZ, Nikolakakos LG, et al. Anterior cervical discectomy and fusion associated complications. Spine (Phila Pa 1976). 2007. 32(21): 2310-7.

7. Lowery GL, McDonough RF. The significance of hardware failure in anterior cervical plate fixation. Patients with 2- to 7-year follow-up. Spine (Phila Pa 1976). 1998. 23(2): 181-6; discussion 186-7.

8. Hirabayashi K, Miyakawa J, Satomi K, Maruyama T, Wakano K. Operative results and postoperative progression of ossification among patients with ossification of cervical posterior longitudinal ligament. Spine (Phila Pa 1976). 1981. 6(4): 354-64.

9. Cho SK, Kim JS, Overley SC, Merrill RK. Cervical Laminoplasty: Indications, Surgical Considerations, and Clinical Outcomes. J Am Acad Orthop Surg. 2018. 26(7): e142-e152. 
10. Kawakami M, Tamaki T, Iwasaki H, Yoshida M, Ando M, Yamada H. A comparative study of surgical approaches for cervical compressive myelopathy. Clin Orthop Relat Res. 2000. (381): 129-36.

11. Seng C, Tow BP, Siddiqui MA, et al. Surgically treated cervical myelopathy: a functional outcome comparison study between multilevel anterior cervical decompression fusion with instrumentation and posterior laminoplasty. Spine J. 2013. 13(7): 723-31.

12. Liu X, Wang H, Zhou Z, Jin A. Anterior decompression and fusion versus posterior laminoplasty for multilevel cervical compressive myelopathy. Orthopedics. 2014. 37(2): e117-22.

13. Miyazaki K, Kirita Y. Extensive simultaneous multisegment laminectomy for myelopathy due to the ossification of the posterior longitudinal ligament in the cervical region. Spine (Phila Pa 1976). 1986. 11(6): $531-42$.

14. Bogduk N, Mercer S. Biomechanics of the cervical spine. I: Normal kinematics. Clin Biomech (Bristol, Avon). 2000. 15(9): 633-48.

15. ODOM GL, FINNEY W, WOODHALL B. Cervical disk lesions. J Am Med Assoc. 1958. 166(1): 23-8.

16. Eck KR, Lenke LG, Bridwell KH, Gilula LA, Lashgari CJ, Riew KD. Radiographic assessment of anterior titanium mesh cages. J Spinal Disord. 2000. 13(6): 501-9; discussion 510.

17. Yang Y, Dai L, Ma L, Gao X, Liu H. Incidence of dysphagia and dysphonia after Hangman's fractures: Evidence from 93 patients. Medicine (Baltimore). 2018. 97(49): e13552.

18. Ghogawala Z, Coumans JV, Benzel EC, Stabile LM, Barker FG 2nd. Ventral versus dorsal decompression for cervical spondylotic myelopathy: surgeons' assessment of eligibility for randomization in a proposed randomized controlled trial: results of a survey of the Cervical Spine Research Society. Spine (Phila Pa 1976). 2007. 32(4): 429-36.

19. Mummaneni PV, Kaiser MG, Matz PG, et al. Cervical surgical techniques for the treatment of cervical spondylotic myelopathy. J Neurosurg Spine. 2009. 11(2): 130-41.

20. Zhou J, Li J, Lin H, Li X, Zhou X, Dong J. A comparison of a self-locking stand-alone cage and anterior cervical plate for ACDF: Minimum 3-year assessment of radiographic and clinical outcomes. Clin Neurol Neurosurg. 2018. 170: 73-78.

21. Yonenobu K, Hosono N, Iwasaki M, Asano M, Ono K. Laminoplasty versus subtotal corpectomy. A comparative study of results in multisegmental cervical spondylotic myelopathy. Spine (Phila Pa 1976). 1992. 17(11): 1281-4.

22. Chen Q, Qin M, Chen F, Ni B, Guo Q, Han Z. Comparison of Outcomes Between Anterior Cervical Decompression and Fusion and Posterior Laminoplasty in the Treatment of 4-Level Cervical Spondylotic Myelopathy. World Neurosurg. 2019. 125: e341-e347.

23. Hirai T, Yoshii T, Sakai K, et al. Long-term results of a prospective study of anterior decompression with fusion and posterior decompression with laminoplasty for treatment of cervical spondylotic myelopathy. J Orthop Sci. 2018. 23(1): 32-38.

24. Wu XD, Wang XW, Yuan W, et al. The effect of multilevel anterior cervical fusion on neck motion. Eur Spine J. 2012. 21(7): 1368-73. 
25. Duetzmann S, Cole T, Ratliff JK. Cervical laminoplasty developments and trends, 2003-2013: a systematic review. J Neurosurg Spine. 2015. 23(1): 24-34.

26. Shigematsu $H$, Ueda $Y$, Takeshima $T$, et al. Degenerative spondylolisthesis does not influence surgical results of laminoplasty in elderly cervical spondylotic myelopathy patients. Eur Spine J. 2010. 19(5): $720-5$.

27. Wang JC, McDonough PW, Kanim LE, Endow KK, Delamarter RB. Increased fusion rates with cervical plating for three-level anterior cervical discectomy and fusion. Spine (Phila Pa 1976). 2001. 26(6): 643-6; discussion 646-7.

28. De la Garza-Ramos R, Xu R, Ramhmdani S, et al. Long-term clinical outcomes following 3- and 4-level anterior cervical discectomy and fusion. J Neurosurg Spine. 2016. 24(6): 885-91.

29. Hosono N, Yonenobu K, Ono K. Neck and shoulder pain after laminoplasty. A noticeable complication. Spine (Phila Pa 1976). 1996. 21(17): 1969-73.

30. Riew KD, Raich AL, Dettori JR, Heller JG. Neck Pain Following Cervical Laminoplasty: Does Preservation of the C2 Muscle Attachments and/or C7 Matter. Evid Based Spine Care J. 2013. 4(1): 42-53.

31. Chiba K, Ogawa Y, Ishii K, et al. Long-term results of expansive open-door laminoplasty for cervical myelopathy-average 14-year follow-up study. Spine (Phila Pa 1976). 2006. 31(26): 2998-3005.

32. Tortolani PJ, Cunningham BW, Vigna F, Hu N, Zorn CM, McAfee PC. A comparison of retraction pressure during anterior cervical plate surgery and cervical disc replacement: a cadaveric study. $\mathrm{J}$ Spinal Disord Tech. 2006. 19(5): 312-7.

33. Lee MJ, Bazaz R, Furey CG, Yoo J. Influence of anterior cervical plate design on Dysphagia: a 2-year prospective longitudinal follow-up study. J Spinal Disord Tech. 2005. 18(5): 406-9.

34. Barbagallo GM, Romano D, Certo F, Milone P, Albanese V. Zero-P: a new zero-profile cage-plate device for single and multilevel ACDF. A single institution series with four years maximum follow-up and review of the literature on zero-profile devices. Eur Spine J. 2013. 22 Suppl 6: S868-78.

35. Shou F, Li Z, Wang H, Yan C, Liu Q, Xiao C. Prevalence of C5 nerve root palsy after cervical decompressive surgery: a meta-analysis. Eur Spine J. 2015. 24(12): 2724-34.

36. Tsuji T, Matsumoto M, Nakamura $M$, et al. Factors associated with postoperative $C 5$ palsy after expansive open-door laminoplasty: retrospective cohort study using multivariable analysis. Eur Spine J. 2017. 26(9): 2410-2416.

37. Katsumi K, Yamazaki A, Watanabe K, Ohashi M, Shoji H. Can prophylactic bilateral C4/C5 foraminotomy prevent postoperative $\mathrm{C} 5$ palsy after open-door laminoplasty?: a prospective study. Spine (Phila Pa 1976). 2012. 37(9): 748-54.

\section{Figures}


Figure 1

ACDF treatment for multisegments CS: A.) preoperative anteroposterior radiograph; B.) preoperative lateral radiograph; $\mathbf{C}-\mathbf{D}$.) preoperative hyperextension and flexion radiograph; E.) preoperative cervical MR; F.) preoperative incision; $\mathbf{G}$.) intraoperative incision; $\mathbf{H}$.) postoperative anteroposterior radiograph; I.) postoperative lateral radiograph; J-L.) postoperative CT and X-ray at the follow-up; $\mathbf{M}-\mathbf{N}$.) postoperative hyperextension and flexion radiograph, and $\mathbf{0}$.) postoperative incision.

\section{Figure 2}

LAMP treatment for multisegments CS. A.) preoperative anteroposterior radiograph; B.) preoperative lateral radiograph; $\mathbf{C}$-D.) preoperative hyperextension and flexion radiograph; E.) preoperative cervical MR; F.) postoperative $\mathrm{CT}$; $\mathbf{G}$.) postoperative anteroposterior radiograph; and $\mathbf{H}$.) postoperative lateral radiograph.

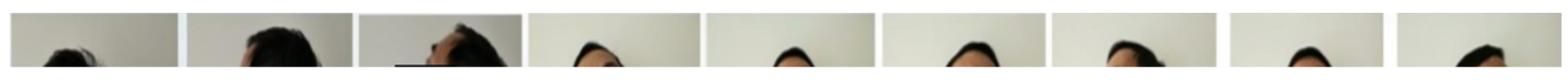

\section{Figure 3}

Measurement of cervical flexion and extension, lateral flexion, and axial rotation angle at postoperative follow-up. A.) cervical hyperflexion position; B.) neutral lateral position of the cervical spine; C.) cervical hyperextension position; D.) right cervical flexion position; E.) neutral position of the cervical spine; F.) left cervical flexion position; G.) right axial rotation position of the cervical spine; $\mathbf{H}_{\text {.) }}$ neutral position of the cervical spine, and $\mathbf{I}$.) left axial rotation position of the cervical spine. 